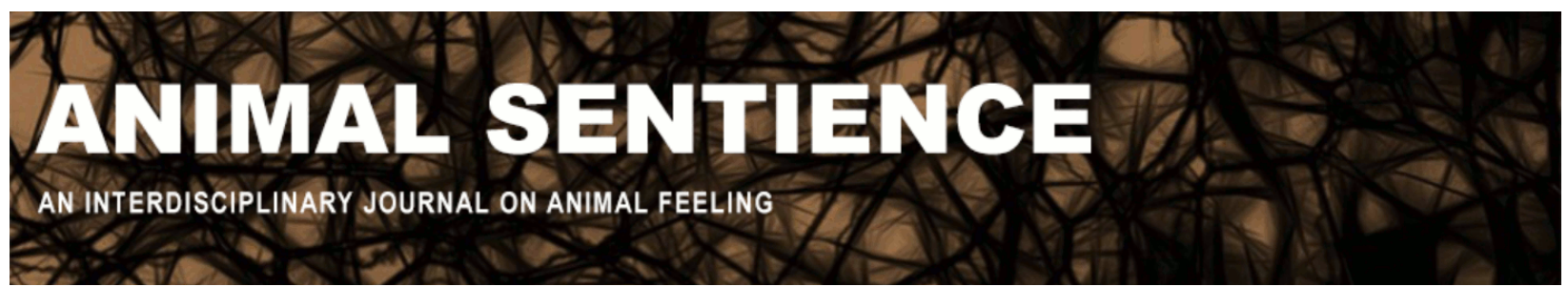

Kaplan, Gisela (2019) Mirror neurons and humanity's dark side. Animal Sentience 23(24)

DOI: $10.51291 / 2377-7478.1401$

Date of submission: 2019-02-04

Date of acceptance: 2019-02-18 (c) 


\title{
Mirror neurons and humanity's dark side
}

Commentary on Chapman \& Huffman on Human Difference

\author{
Gisela Kaplan \\ School of Science and Technology \\ University of New England (UNE), Armidale, New South Wales, Australia
}

\begin{abstract}
The last two decades have revealed brain mechanisms in birds and primates showing that, contrary to earlier prejudices, some birds can do things (cognitive and affective) on par with or even better than great apes and humans. The old dichotomies are breaking down; but the dark side is that these insights come at a time in the Anthropocene when humans have caused and continue to cause mass extinctions.
\end{abstract}

Gisela Kaplan is emeritus professor in animal behavior at UNE. Her two careers span social sciences and animal behavior (two PhDs). Her publications include over 250 research papers (field research) and 23 books (on orangutans, dogs, animal communication, and comparative cognition but predominantly bird behavior). She is a life member of the IPS and an elected honorary fellow of the AOU, and was awarded an honorary D.Sc.

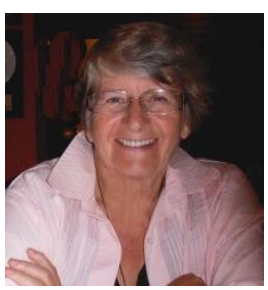
Website

Chapman \& Huffman (2018) (C \& H) raise a number of familiar and highly problematic questions that have occupied philosophers throughout recorded history. As a scientist, I am satisfied that we have made very exciting progress in recent decades. I also disagree profoundly with those philosophers from Aristotle's scala naturae to Descartes who have vigorously denied that animals can feel or think (Westling 2014). We have discovered the regulatory mechanisms of hormones and the intricacies of mammalian and avian brains. As C \& H note, we have been able to show that many facets of human behavior and ability are indeed not 'unique'. There are antecedents in the behavior, the perceptual endowments and cognitive abilities of nonhuman animals. We even have evidence of animals exceeding human abilities and performance (Rogers and Kaplan 2004).

Vocal learning, with its complex neural apparatus, is an ability that has been bestowed on very few classes of animals, largely humans and birds (Wilbrecht and Nottebohm 2003; Jarvis 2007). Brain organization can be permanently altered by environmental influences such as light (Rogers 1982). Evidence of the overall similarity between the brain architecture of humans and birds has resulted in the renaming of all parts of the bird brain (Jarvis et al. 2005). Biological movement has been studied extensively in vertebrates, along with perceptual abilities, particularly vision, including the ability to assess motion (Regolin et al. 2000; Vallortigara et al. 2005; Miura and Matsushima 2016). Our laboratory has tested di- and trichromatic common marmosets (Saito et al. 2005) and shown that marmoset females can perceive biological motion, as can chickens, cats, baboons, chimpanzees and humans (Parron et al. 2007; Simion et al. 2008; 
Brown et al. 2010). Dunbar (2009) has proposed a social brain hypothesis based on the identification of neural correlates of social cognition and the discovery of mirror neurons, first in primates (Di Pellegrino et al. 1992), then in birds (Prather 2008) and finally, in humans (Ferrari and Rizzolati 2014; Rizzolatti and Fogassi 2014).

The implications of mirror neurons have been particularly fascinating. They can process a pattern of visual or auditory input and associate it with the motor output that produces the same pattern. When a song is heard, the same neurons fire in the listening bird as when it is singing the song itself (Feenders et al. 2008). This explains the learning of sound and movement patterns (mimicry and imitation) which was once thought to be uniquely human (Lamm and Majdandžić 2015). If an avian or primate brain is able to equate the movements of someone else with its own movements, perhaps it can also detect other concrete or abstract states of mind such as empathy (Gallese 2001, 2007) and the intentions of others (lacoboni et al. 2005; Kaplan 2015).

My second response to the role of humans and their position relative to animals is probably far more pessimistic than C \& H's. We are one of the two species in the entire living world that kill not to eat but to have fun (Ghiglieri 1999). To this day, I stand in disbelief when I see a shooter gun down a bird from the sky not because the shooter needs it to survive but for sport, destroying a life and a family without remorse. No carnivore behaves as wantonly as do humans (and, as discovered in the 1990s, also chimpanzees; Wrangham and Peterson 1997). Only chimpanzees and humans go to war (Aureli et al. 2008; de Waal and de Waal 2007), get excited in seeking a fight, and fix targets with the intention to kill and enjoy the bloodbath (Torres 2018). Humans are unique in deliberately inflicting pain, subjugation and torture on others of their own kind, not for defense but because they can; and we are terrifyingly innovative in new techniques and new forms of killing (Baron-Cohen 2011).

At no time in history have we so decoupled from the natural world as today (Challenger 2012), falsely believing that we no longer need it. We don't just have the ability to destroy whole ecosystems with little effort: we do so, readily, if there is a dollar to be made. We are beholden to modern gadgets and technology but have not inquired enough into what their effects might be on wildlife (Williams 2009). Human activities and innovative technology have accelerated the destruction, probably exponentially (Ceballos et al. 2015). Technology has become so deeply embedded as an icon of all that is called progress that it is often not just accepted but criticism is taboo (Feenberg 2008). We could destroy the whole world if we wanted to, yet most people remain confident that we can solve any problem if it really becomes acute. Even if this is true: at what cost (Kaplan 2016)?

\section{References}

Aureli, F., Scaffner, C.M., Verpooten, J., Slater, K., \& Ramos-Fernandez, G. (2006) Raiding parties of male spider monkeys: Insights into human warfare? American Journal of Physical Anthropology, 131(4), 486-497.

Baron-Cohen, S. (2011) Zero degrees of empathy: A new theory of human cruelty (vol. 30). UK: Penguin.

Brown, J., Kaplan, G., Rogers, L.J., \& Vallortigara, G. (2010) Perception of biological motion in common marmosets (Callithrix jacchus): By females only. Animal Cognition, 13, 555-564. 
Ceballos, G., Ehrlich, P.R., Barnosky, A.D., García, A., Pringle, R.M., \& Palmer, T.M. (2015) Accelerated modern human-induced species losses: Entering the sixth mass extinction. Science Advances, 1(5), e1400253.

Challenger, M. (2012) On extinction: How we became estranged from nature. Counterpoint Press.

Chapman, C. A., \& Huffman, M.A. (2018) Why do we want to think humans are different? Animal Sentience 23(1).

De Waal, F., \& Waal, F.B. (2007) Chimpanzee politics: Power and sex among apes. JHU Press.

Di Pellegrino, G., Fadiga, L., Fogassi, L., Gallese, V., \& Rizzolatti, G. (1992) Understanding motor events: A neurophysiological study. Experimental Brain Research, 91(1), 176-180.

Dunbar, R.I.M. (2009) The social brain hypothesis and its implications for social evolution. Annals of Human Biology, 36(5), 562-572.

Feenberg, A. (2008) From critical theory of technology to the rational critique of rationality. Social Epistemology, 22(1), 5-28.

Feenders, G., Liedvogel, M., Rivas, M., Zapka, M., Horita, H., Hara, E., Wada, K., Mouritsen, H., \& Jarvis, E.D. (2008) Molecular mapping of movement-associated areas in the avian brain: A motor theory for vocal learning origin. PLOS ONE, 3(3), e1768.

Ferrari, P.F., \& Rizzolatti, G. (2014) Mirror neuron research: The past and the future. Philosophical Transactions of the Royal Society B, 369, 20130169.

Gallese, V. (2001) The 'Shared Manifold' Hypothesis. From mirror neurons to empathy. Journal of Consciousness Studies, 8(5-7), 33-50.

Gallese, V. (2007) Before and below 'theory of mind': Embodied simulation and the neural correlates of social cognition. Philosophical Transactions of the Royal Society of London B: Biological Sciences, 362(1480), 659-669.

Ghiglieri, M.P. (1999) The dark side of man: Tracing the origins of male violence. New York: Perseus Publishing.

lacoboni, M., Molnar-Szakacs, I., Gallese, V., Buccino, G., Mazziotta, J.C., \& Rizzolatti, G. (2005) Grasping the intentions of others with one's own mirror neuron system. PLoS Biology, 3(3), e79.

Jarvis, E.D. (2007) Neural systems for vocal learning in birds and humans: A synopsis. Journal of Ornithology, 148(1), 35-44.

Jarvis, E.D., Güntürkün, O., Bruce, L., Csillag, A., Karten, H., Kuenzel, W., Medina, L., Paxinos, G., Perkel, D.J., Shimizu, T., \& Striedter, G. (2005) Avian brains and a new understanding of vertebrate brain evolution. Nature Reviews Neuroscience, 6(2), 151-159.

Kaplan, G. (2015) Bird minds. Cognition and behaviour of Australian native species. Melbourne: CSIRO Publishing.

Kaplan, G. (2016) Don Quixote's windmills. In M. Tønnessen, K. Armstrong Oma, \& S. Rattasepp (Eds.), Thinking about animals in the age of the Anthropocene (Ch. 14). Lanham, MD, and London: Lexington Books, pp. 284-305.

Lamm, C., \& Majdandžić, J. (2015) The role of shared neural activations, mirror neurons, and morality in empathy-a critical comment. Neuroscience Research, 90, 15-24.

Miura, M., \& Matsushima, T. (2016) Biological motion facilitates filial imprinting. Animal Behaviour, 116, 171-180. 
Parron, C., Deruelle, C., \& Fagot, J. (2007) Processing of biological motion point-light displays by baboons (Papio papio). Journal of Experimental Psychology: Animal Behavior Processes, 33(4), 381-391.

Prather, J.F., Peters, S., Nowicki, S., \& Mooney, R. (2008) Precise auditory-vocal mirroring in neurons for learned vocal communication. Nature, 451, 305-310.

Regolin, L., Tommasi, L., \& Vallortigara, G. (2000) Visual perception of biological motion in newly hatched chicks as revealed by an imprinting procedure. Animal Cognition, 3, 53-60.

Rizzolatti, G., \& Fogassi, L. (2014) The mirror mechanism: Recent findings and perspectives. Philosophical Transactions of the Royal Society B, 69, 20130420.

Rogers, L.J. (1982) Light experience and asymmetry of brain function in chickens. Nature, 297(5863), 223.

Rogers, L.J., \& Kaplan, G. (2004) All animals are not equal: The interface between scientific knowledge and the legislation for animal rights. In C. R. Sunstein \& M. C. Nussbaum (Eds.), Animal rights: Law and policy. Oxford: Oxford University Press, pp. 175-204.

Saito, A., Mikami, A., Kawamura, S., Ueno, Y., Hiramatsu, C., Widayati. K.A., Suryobroto, B., Teramoto, M., Mori, Y., Nagano, K., \& Fujita, K. (2005) Advantages of dichromats over trichromats in discrimination of color-camouflaged stimuli in non-human primates. American Journal of Primatology, 67, 425-436.

Simion, F., Regolin, L., \& Bulf, H. (2008) A predisposition for biological motion in the newborn baby. Proceedings of the National Academy of Science, 105(2), 809-813.

Torres, P. (2018) Who would destroy the world? Omnicidal agents and related phenomena. Aggression and Violent Behavior, 39, 129-138.

Vallortigara, G., Regolin, L., \& Marconato, F. (2005) Visually inexperienced chicks exhibit spontaneous preference for biological motion patterns. PLoS Biology, 3, 1312e1316.

Westling, L. (2014) The logos of the living world. Merleau-Ponty, animals and language. New York: Fordham University Press.

Wilbrecht, L., \& Nottebohm, F. (2003) Vocal learning in birds and humans. Mental Retardation and Developmental Disabilities Research Reviews, 9(3), 135-148.

Williams, L. (2009) Haraway contra Deleuze \& Guattrari. The question of animals. Communication, Politics \& Culture, 42(1), 42- 54.

Wrangham, R.W., \& Peterson, D. (1996) Demonic males: Apes and the origins of human violence. Boston, MA: Houghton Mifflin Harcourt. 